the determination of three great natural standards---of length, time, and mass, and their combinations.

Another branch of the general subject is the Measurement of Light, which may be divided into two principal sections, that including the measurement of the wavelength of lights of different colours, and the angle of polarization, which belongs purely and entirely to physical science ; and the measurement of the intensity of light by photometry, which, while involving also physical problems of the highest order, has an important bearing also upon applied science. 'The principal methods that have been hitherto employed in photometry are by the comparison of shadows, that of Rumford and Bouguer; by employing a screen of paper with a grease-spot, the lights to be compared being so adjusted that the spot does not differ in appearance from the rest of the paper, Bunsen's method; Elster's, by determining in combustion the amount of carbon contained in a given volume of a gas; and the one lately introduced by Prof. Adams and Dr. Werner Siemens, by measuring the variation in the electrical resistance of selenium, under varying intensities of light.

Before concluding, I wish to call your attention to two measuring instruments which do not fall within the range of any of the divisions before indicated. The first is an apparatus designed chiefly by my brother, Dr. Werner Siemens, by which a stream composed of alcohol and water, mixed in any proportion, is measured in such a manner that one train of counter wheels records the volume of the mixed liquid ; whilst a second counter gives a true record of the amount of absolute alcohol contained in it. The principle upon which this measuring apparatus acts may be shortly described thus:-The volume of liquid is passed through a revolving drum, divided into three compartments by radial divisions, and not dissimilar in appearance to an ordinary wet gas-meter; the revolutions of this drum produce the record of the total volume of passing liquid. The liquid on its way to the measuring drum passes through a receiver containing a float of thin metal filled with proof spirit, which fioat is partially supported by means of a carefully-adjusted spring, and its position determines that of a lever, the angular position of which causes the alcohol counter to rotate more or less for every revolution of the measuring drum. Thus, if water only passes through the apparatus the lever in question stands at its lowest position, when the rotative motion of the drum will not be communicated to the alcohol counter, but in proportion as the lever ascends a greater proportion of the motion of the drum will be communicated to the alcohol counter, and this motion is rendered strictly proportionate to the alcohol contained in the liquid, allowance being made in the instrument for the change of volume due to chemical affinity between the two liquids. Several thousand instruments of this description are employed by the Russian Government in controlling the production of spirits in that empire, whereby a large staff of officials is saved, and a perfectly just and technically unobjectionable method is established for levying the excise dues.

Another instrument, not belonging to any of the classes enumerated, is one for measuring the depth of the sea without a sounding line, which has recently been designed by me, and described in a paper communicated to the Royal Society. Advantage is taken in the construction of this instrument, of certain variations in the total attraction of the earth, which must be attributable to a depth of water intervening between the instrument and the solid constituents of the earth. It can be proved mathematically that the total gravitation of the earth diminishes proportionately with the depth of water, and that if an instrument could be devised to indicate such minute changes in the total attraction upon a scale, the equal divisions on that scale would represent equal units of depth. (See NATURE. vol. xiii., p. 43I.)

Gravitation is represented in this instrument by a column of mercury resting upon a corrugated diaphragm of thin steel plate, which in its turn is supported by the elastic force of carefully tempered springs representing a force independent of gravitation. Any change in the force of gravitation must affect the position of this diaphragm and the upper level of the mercury, which causes an air-bubble to travel in a convolute horizontal tube of glass placed upon a graduated scale, the divisions of which are made to signify fathoms of depth. Special arrangements were necessary in order to make this instrument parathermal, or independent of change of temperature, as also independent of atmospheric density, which need not be here described. Suffice it to say that the instrument, which has been placed on board the S. S. Faraday during several of her trips across the Atlantic, has given evidence of a remarkable accordance in its indications with measurements taken by means of Sir William Thomson's excellent pianoforte wire-sounding machine ; and we confidently expect that it will prove a useful instrument for warning mariners of the approach of danger, and for determining their position on seas, the soundings of which are known.

Another variety of this instrument is the horizontal attraction meter, by which it will be possible to obtain continuous records of the diurnal changes in the attraction of the sun and moon as influencing the tides. This instrument belongs, however, rather to the domain of physics than to that of mechanical science.

These general remarks upon the subject of measurement may suffice to call your attention to its importance, several branches of which, sthose of Linear, Cubical, and Electrical Measurement, will now be dealt with.

The discussions which will follow these addresses will be carried on under circumstances such as have never before co-operated, namely, the presence of leading men of science of all civilised nations, who will take part in them, and the easy reference which can be had to the most comprehensive collection of models of scientific apparatus-both of modern and ancient-which has ever been brought together.

\section{SCIENCE AT THE MANSION HOUSE}

FOR the first time probably in the history of this country, science has been publicly acknowledged as a great force or power in the kingdom, on a level with literature and art. This, we think, is the legitimate conclusion to be drawn from the entertainment on Saturday by the Lord Mayor at the Mansion House of so many distinguished representatives of science, following hard as it did upon the opening of the loan collection by her Majesty the Queen. The company was numerousthere were about 300 present-as well as distinguished, and included several eminent foreign representatives of science, who have come over to the opening of the loan collection. The meeting was quite as successful as such meetings usually are, and the speeches on the whole much more sensible and appropriate. 'The following report of the speeches we take from the Morning Post:-

The Lard Mayor, in proposing the toast of the evening, "The Representatives of Science," spoke very happily. We were scarcely, he said, conscious of what we owed to science. If the inventor of the first small crane or lever for lifting water from a well were to come upon the scene now-a-days he would have some difficulty in persuading himself that it was the same world, and not some kind of paradise very far in advance of the world with which, in his day, that person was acquainted. Science was one of the mightiest of all the intellectual pursuits that man could follow. His Lordship said he had an intense admiration for the representatives of literature, but he could hardly express the feelings with which he regarded the men who laboured in the various phases of science. What did we owe to it? and what 
were we coming to? 'To science we owed every easement we enjoyed in the work of our daily life. Science enabled us, in comparison with past generations, to live our lives over and over again. It enabled us to travel such mighty distances within so short a space of time as a few years ago would have been inconceivable; and, what with the aid of the electric telegraph, it placed us in almost immediate communication with nearly all parts of the world. Having referred to the vast saving of manual labour wibich had been effected through the aid of science by machinery and appliances of various kinds, his Lordship expressed his gratification at the presence of representatives of so many branches of science.

Dr. Hooker, who was the first to respond, remarked that the occasion might be regarded as marking an imporiant epoch in the history of science. It had been his pleasure to attend the various exhibicions for the promotion of science and art which had been held in this country and abroad by our own and by other Governments since 1851 , and not only to study their contents but also to inquire into their origin and connection, and what might be called their individuality. With respect to the exhibition which the present banquet might be said to commemorate, he could see many marks which distinguished it from those that had gone before it. It had been brought to its present remarkable state by the indomitable energy of a very few workers whom it might be invidious to particularise, though he could not forbear mentioning the name of Mr. Lockyer. Originating as it did almost spontaneously, it had received the support of the Government from the active interest that was taken in it by the Lord President and the Vice-President of the Council, and from the diplomatic action which restited in getting foreign Governments to send their delegates to visit the exhibition and to take part in conferences on the occasion of its opening. It had derived no small support from the countenance which had been graciously bestowed upon it by the Queen. In continuation, Dr. Hooker said, look at the state of science now and what it was 300 years ago. It had advanced with such strides as had marked the progress of no other branch of intellectual pursuit. Compare, or rather contrast, the progress of science in modern times with that of literature and the fine arts. With regard to literature, as with regard to the fine arts in this country, more especially in the case of sculpture and architeciure, we had to look back ages almost to find a starting-point in their gereral progress, and even in the case of the most modern of the tine arts-paintin - we were referred back to the cradles of its tirth in Italy, Spain, and the Low Countries. With regard to the Exhibition for the Advancement of Scisnce, what was to be its future? Was it to be a matter of a few weeks or months, and then to pass away for ever? It was to be hoped not. It was the earnest desire of scientific men to form the nucleus of a great rational museum of a permanent character for the benefit not cnly of scientific men but for the benefit of the public in general, and be feit sure that science would not look to the public in vain for aid in the endeavour to realise that important object. It was an object worthy of great and noble efforts, and he felt assured that such effusts would not be wanting on the part of the City of London.

Afcex a few remarks from Sir John Hawkshaw, Sir George Airy, the Astronomer Royal, replied for that branch of the toast which he represented, and spoke of science under two heads, which, for want of better terms, he said he might describe as piactical and contemplative science. Of the present stat of practical science it was impossible to speak too highly. It was impossible for any one who had even a partial acquaintance with what was going on in our manufacturing districts especially, and in all those labours which were for the benefit of mankınd, not to be struck with the enormous amount of ingenuity and enterprise which were brought to bear upon those industries with a view to material gain. Material gain was the aim of practical science. As for what he termed the contemplative branch of science, which embraced especially all those pursuits relating to the constifution of nature, the object in that case was not material gain or personal advantage, but the results at which it aimed were in their way not inferior to or less welcome than those of practical science.

Mr. Justice Grove in proposing "The Health of the Lord Mayor," humorously remarked that his lordship when inviting such a body of representatives of science to partake of his splendid hospitality, must have been actuated, not only by a lively sense of favours received, but also by a lively sense of favours to come. Mindful of what science had done for commerce and manufactures in the past, the first magistrate of the city of London had doubtless an eye at the same time to the advantages which manufactures and commerce would reap from the labours of science in the future. There was nothing in which the Lord Mayor could do himself more honour than in entertaining at his table the votaries of science, to whom, on the other hand, nothing could be more gratifying or encouraging than this mark of recognition and appreciation on his part of the value of their labours.

To the toast of "The Foreign Representatives of Science," Prof. Blaserna responded.

Altogether, we think, both the Lord Mayor and the representatives of science are to be congratulated on the success of this entertainment, which will no doubt form a precedent for future ones of a similar kind.

\section{NOTES}

Col. Prejevalsixy is about to set out on a new exploring journey into Central Asia, which will probably last for about three years. His purpose is to explore especially the basin of the Lob-nor from Thian-shan to the Himalayas. Col. Prejevalsky proposes to visit this summer Eastern Thian-shan from Kuloga to Hama, and to pass the winter upo 1 the Lob-not and in the deserts which extend to the east of thi; $l \neq k$, mainly to solve the question as to wild horses and camels. Next spring he will ob. serve the migrations of birds on Lob-nor and prozeed to Lhassa. He will then explore the upper course of the Brahamapootra and the northern slopes of the Himalayas, as also Eastern 'Thibet and Southern China, and if circumstancrs permit, he will return by Western Thibet and enter Russia by Kashgar. The programme of the expedition is as follows:-I. Geographical and thnographical descriptions. 2. An itinerary sketch at sight. 3. Astronomical determinations of places. 4. Meteorological, psychometric, and hypsometric observations. 5. Observations of mamma!s and birds. 6. Botani:al, zoologica!, and mineralogical collections. 7. Piotographic skeches. The Rusian Gecyraphical Society has expressed its emphatic approval of the programme, and the Emperor has ordered 24,740 ruubles to be devoted to the expedition from the treasury.

From Commander Cookson we hear that H.M.S. Peirel is bringing home two living specimens of the Giant Tortoise of the Galapagos Islands, frum Albemarle Island. A large supply of food was provided, and if this does not fail, and at the same time if the cold in the region of Cape Horn has not proved too intense, we may hope to see the specimens alive, for the first time in this country, during next month.

From the Rochester Democrat and Chronicle (U.S.) we learn that a gentlem in of Rochester, New York, who does not wish his name to be published, has, through Prof. Henry A. Ward of that city, given to the University of Virginia, a sum of $5,500 l$. to be expended in the formation of a fully appointed cabinet of the 